\title{
World Population Issues and Programs
}

\author{
MILOS MACURA
}

Professor

Economic Institute

Belgrad, Yugoslavia

A most critical feature of the current and the future demographic situation appears to be the phenomenon of differential fertility. Because of its high and low extremes, and the differentiating effects on growth, size and structure of populations, fertility will continue to attract the attention of scholars and policymakers more than any other demographic variable. Of course this does not imply that questions related to mortality and longevity, internal migration, re-distribution and urban growth, age structure and the ageing process, or international migration will be less interesting and important. It simply means that given the demographic conditions of the past decades, fertility has become the most critical variable.

It should be recalled that it was the improvement in the human condition that has enabled man to live longer. This, which translates at the aggregate level to a fall in mortality, allowed populations in countries going through the industrial revolution to grow much faster than before. Today, a different set of conditions is prolonging life-expectancy in pre-industrial societies, resulting in unprecedented population growth throughout the economically less developed world. In the past, and the present, decline in mortality has been and is a major source of population growth on two different but interrelated grounds. Firstly, there are the growing number of survivors as life-expectancy is extended. Secondly, there is the increase in the reproductive stock which yields a higher number of births despite eventual declines in fertility. These are wellknown facts in demography which however must not be neglected when the demographic conditions of the contemporary world are examined.

As a consequence of these factors, world population has climbed from one billion in 1800 to 2.5 billion in 1950, and 4.4 billion in 1980. It is likely to reach 6.2 billion by the year 2000, and to double during the next century. Amongst the many implications of this accelerated trend, the following deserve special mention.

With a gain of 5 billion inhabitants over the past and present century, our planet will be fairly densely populated. With an increase of a further 6 billion over the next century it would become well-populated. Density would rise 
from 7 to 88 persons per square kilometre over this period, changing significantly the man-resource ratio. Whereas rapid population growth worked in favor of mankind and progress in the past, this is no longer so today, nor will it be tomorrow. Indeed, there are numerous ecological, economic, social, anthropological and ethical arguments in favor of a state of demographic stability.

Never in history have patterns of world population growth been as diverse as today, nor have variations in vital rates been as wide as they are now. The death rate ranges from as high as 20 per 1000 in Africa and some Asian countries, to as low as 6 per 1000 in Latin America and Japan. Yet the longest life expectancy is not even found in Latin America but in northwest Europe, Northern America and Japan. Birth rates of 50 per 1000 , corresponding to a gross reproduction rate (GRR) of 3.50 persist in some African countries. By contrast, Europe has birth rates slightly above 10 per 1000 and a GRR below unity. Consequently, rates of natural increase vary from 3.5 percent to less than zero. ${ }^{1}$ These variations are not influenced by race, color, climate or other natural factors, but by historical differences and stages of development.

At the current level of mortality, life expectancy is likely to grow more slowly than before. There are ample prospects for significant gains in life expectancy in Africa and South Asia and to some extent in Latin America and East Asia. There are also prospects for gains elsewhere in the world thanks to scientific advances and medical progress. All this will be a source of population growth, but not on the scale experienced in the past. Nevertheless, with the ageing of the population, and as an effect of it, mortality will increasingly be felt as a negative growth component.

Despite the appreciable post-war revival, international migration is unlikely to be a significant component of regional population growth. The conditions for, and effects of current and future migration are not comparable with those of the great migrations of the late Nineteenth and early Twentieth Centuries. No area can be as receptive as America, or to a much lesser extent, Australia, were. The earlier complementariness between population-rich and resourcerich areas has disappeared; no new mechanism has emerged; growing nationalism is tending to impose restrictions on human movement.

With mortality and migration declining as generators of national population growth, fertility is once again becoming the critical factor. Differential fertility acts as such at the world level, producing different dynamic and structural effects. Of course, neither high nor low fertility is an abstract or simple concept. Although determined by the number of births and its relationship to the size of population and the reproductive stock, they also depend on life expectancy at birth, replacement of cohorts, and in the final analysis on reproduction of the population. It is through these relationships that fertility is either excessive, sufficient, or deficient (Table 1).

1 United Nations, World Population Trends and Prospects by Country, 1950-2000: Summary Report of the 1978 Assessment, New York, 1979. 
Regional differences in fertility derive from both high and low fertility. Over time, differences narrow in some respects and expand in others. Thus for example, the ratio between the highest and lowest regional birth rate - in Africa and Europe respectively - after the Second World War was 2.4: 1. Today it is $3.2: 1$, and by the end of the century it is projected to be $2.5: 1$. However, the ratio of the number of children born in these two regions was 1.4 : 1 ; today it is $3.0: 1$, and the estimate for the end of the century is $4.7: 1$.

T able 1. Fertility related indices - selected countries: $1975-80$.

\begin{tabular}{|c|c|c|c|c|c|c|c|}
\hline Country & GRR & CBR & CDR & $\mathrm{RNI}$ & $\mathrm{e}_{0}^{0}$ fem. & $0-14$ & $65+$ \\
\hline Kenya & 3.60 & 50.8 & 12.4 & 38.4 & 57.5 & 43.1 & 3.3 \\
\hline Nigeria & 3.40 & 49.8 & 17.8 & 32.0 & 49.2 & 47.1 & 2.4 \\
\hline Algeria & 3.55 & 47.5 & 13.4 & 34.1 & 57.4 & 47.9 & 3.9 \\
\hline Bangladesh & 3.25 & 47.0 & 17.6 & 29.4 & 47.0 & 46.3 & 2.7 \\
\hline Mexico & 3.06 & 41.7 & 7.6 & 34.1 & 67.4 & 45.9 & 3.5 \\
\hline India & 2.55 & 36.9 & 14.0 & 22.9 & 51.0 & 41.9 & 2.9 \\
\hline Indonesia & 2.40 & 37.9 & 14.6 & 23.3 & 51.3 & 43.7 & 2.5 \\
\hline Brasil & 2.39 & 36.0 & 7.8 & 28.2 & 66.7 & 42.0 & 3.2 \\
\hline China & 1.52 & 22.1 & 8.8 & 13.3 & 65.9 & 34.9 & 5.3 \\
\hline Spain & 1.27 & 17.9 & 8.1 & 9.8 & 75.5 & 27.6 & 10.0 \\
\hline USSR & 1.16 & 18.3 & 8.9 & 9.4 & 74.3 & 26.1 & 8.9 \\
\hline Greece & 1.12 & 15.6 & 9.5 & 6.1 & 75.0 & 23.9 & 12.2 \\
\hline Japan & 0.89 & 15.0 & 6.5 & 8.5 & 77.4 & 24.3 & 7.9 \\
\hline USA & 0.89 & 15.2 & 9.1 & 6.1 & 77.0 & 25.1 & 10.5 \\
\hline Sweden & 0.82 & 11.8 & 11.3 & 0.5 & 77.9 & 20.7 & 15.1 \\
\hline Austria & 0.82 & 11.5 & 12.6 & -1.1 & 75.3 & 23.3 & 15.0 \\
\hline Germany F.R. & 0.70 & 9.8 & 12.8 & -3.0 & 75.2 & 21.8 & 14.3 \\
\hline
\end{tabular}

Source: United Nations, op.cit.

Note: $\quad$ GRR $=$ Gross Reproduction Rate; $\mathrm{CBR}=$ Crude Birth Rate; $\mathrm{CDR}=$ Crude Death Rate; RNI = Rate of Natural Increase (per 1000 population); e $e_{n}^{0}=$ life expectancy at birth for females; $0-14$ and $65+=$ percentage of the age group in total population.

Differences are much wider at the national than the regional population level. The extremes, such as GRRs of 3.60 and 0.70 , represent the maximal difference. The top values will gradually diminish and the lowest values have probably bottomed out so we can anticipate a period in which the gap begins to narrow. But other populations in fertility decline could drop to the lowest level meanwhile so that the prospects for unification are quite uncertain.

\section{Fertility: a problem of too many but also too few}

What are the problems arising from current population trends? Leaving to one side the problems of economic and social development, which were dealt 
with in relation to population issues at the 1978 Helsinki Conference, I would suggest that these problems concern the individual and the population alike - the micro and the macro levels of the process.

Excessively high fertility, with adverse effects on maternal, child and family well-being and associated with excessive mortality, particularly of infants, and all this in the context of a young age structure - this is the reproduction pattern of most of Africa and South Asia. A similar, yet different, pattern prevails in Latin America - different in that mortality is low, but similar on the other characteristics. The combined population of these regions in 1950 was about 1.1. billion; according to the United Nations projections it could reach 3.6 billion in 2000 .

High fertility combined with a relatively high life expectancy, and an age structure dominated by the middle-aged, is characteristic of East Asia and Oceania, with the exception of Japan and Australia. In 1950 the total population of this area was 592 million, and in 2000 it is likely to be close to 1.3 billion.

The pattern in the USSR and parts of Eastern and Southern Europe includes moderately high fertility and a low death rate, a growing life-expectancy, and a low proportion of the aged, resulting in substantial natural increase. Demographic transition here is of recent date but it is spreading fast, reducing the reproduction rate to below unity, although leaving pockets of high fertility in its wake. The combined population of these countries in 1950 was about 300 million. In 2000 it could reach about 500 million.

A gross reproduction rate below replacement and high life expectancy at birth are common features of the populations in most of Northern and Western Europe, Northern America, Japan, Australia and a few countries in Southeast Europe. Owing to different time schedules of transition and demographic ageing, the age patterns differ markedly within this group, as do crude birth and death rates. Most of these populations are still growing, but four have reached a stage of negative growth which could last for some time. The total population of this group was above 500 million in 1950 and is projected at 700 million in 2000 .

To sum up, I would suggest that some three-quarters of the world's population faces a further fertility decline while about a quarter already needs, or will need in the next few decades, to restore low fertility to its proper condition.

Amongst the host of population problems, fertility is not just a problem of too many births, but of too few as well. Stabilizing fertility, and indeed demographic conditions generally, is a problem that faces not only the poor and the economically less-developed countries, but the affluent and industrialized as well. 


\section{Has the population policy been successful?}

While stressing aggregate reproduction and the community's need to endure and progress, modern policy regarding fertility must appreciate the human aspect of reproduction and safeguard the rights of the individual. I mean not only the fundamental human rights, but also the right of the mother, child and family to be protected by the community and, particularly, the right of the individual to freely decide on the size of his or her family.

Since in both high and low fertility countries the outcome of individual decisions on birth tends to be at variance with the level of fertility required for reproduction of the population, social intervention in one direction or another seems to be indispensable. In both cases, economic, social and institutional conditions must be fostered, and social standards, values and ethical norms inculcated which, in concert, will promote individual reproductive behavior in line with socially-desired reproduction. In the latter half of the Twentieth Century, when many aspects of human life have assumed a political dimension, it is not surprising that social intervention in human reproduction has been preempted by government population policy. A genuine search for such policy has been made in several developing countries, with assistance by international agencies, non-governmental organizations and private persons, but it is hard not to make comparisons of those with the democratic and egalitarian approach to population problems developed by the Scandinavian socialists.

After several years of application, the success of population policies is a pertinent and timely question. No straightforward and conclusive answer can be forthcoming because of the many conceptual, methodological and analytical difficulties involved. Interpretations of data, never overabundant anyway, differ substantially as a result, and yield different conclusions. In fact, while some experts seem to claim population programs have been remarkably successful, others argue they are less than adequate.

Extreme as they are, both conclusions seem to be correct in some respects. The number of births, the volume of population increase, and the ineffectiveness demonstrated in managing the demographic, economic and human affairs in the economically less-developed world, seem to suggest that population programs have failed, in the same way as economic and social planning have failed. The world has just not been able to accomodate the bulk of the growing millions at a level above malnutrition, ignorance and slow economic progress, in sharp contrast to the rank abundance on the other side. Similarly, stark neglect of population problems in countries with rapid population growth, or failure to integrate population, social and economic measures - modest as they may be - with a view to speeding up fertility decline, also point to inadequacy.

In this gloom, it is really encouraging to see population programs capable of reaching as much as 75-99 percent of women of reproductive age with information on contraception and make them aware of the possibility of fertility 
control. Conception and birth, traditionally overlain with secrecy, superstition or religious believes, have been unveiled and made a matter of personal choice. This is, without doubt, a significant achievement. But its practical value depends on whether this knowledge is applied or not (Table 2).

$\mathrm{Table} 2$. Total fertility rate, proportion of women aware of contraception, proportion of ever-users and take-up ratio (per 1000).

$\begin{array}{lcccc} & \begin{array}{c}\text { Total fer- } \\ \text { tility rate }\end{array} & \text { Aware } & \text { Ever-users } & \begin{array}{c}\text { Take-up } \\ \text { ratio }\end{array} \\ \text { Bangladesh } & 6.1 & 818 & 136 & 166 \\ \text { Nepal } & 6.0 & 224 & 41 & 183 \\ \text { Pakistan } & 5.8 & 750 & 100 & 133 \\ \text { Mexico } & 5.7 & 895 & 452 & 505 \\ \text { Dom. Republic } & 5.3 & 975 & 473 & 485 \\ \text { Peru } & 5.2 & 820 & 485 & 591 \\ \text { Philippines } & 4.8 & 942 & 575 & 610 \\ \text { Jamaica } & 4.5 & 980 & 659 & 672 \\ \text { Guiana } & 4.4 & 954 & 575 & 603 \\ \text { Columbia } & 4.4 & 958 & 590 & 616 \\ \text { Malaysia } & 4.3 & 919 & 476 & 518 \\ \text { Indonesia } & 4.2 & 768 & 344 & 448 \\ \text { Thailand } & 4.2 & 964 & 452 & 469 \\ \text { Panama } & 4.0 & 986 & 726 & 736 \\ \text { Korea } & 4.0 & 972 & 566 & 582 \\ \text { Fiji } & 3.9 & 999 & 676 & 677 \\ \text { Sri Lanka } & 3.5 & 909 & 432 & 475 \\ \text { Costa Rica } & 3.5 & 995 & 816 & 820\end{array}$

Source of data: E. Grebenik: World Fertility Survey and Its 1980 Conference.

London 1981.

Table 2 shows marked variations in national fertility rates which are attributable in part to the proportion of women acquainted with and using contraception. If the series is taken as portraying the beginning of a process, the population programs of most of the countries in the table could be considered successful. If, however, the criterion of program effectiveness is taken as being use of contraception by two-thirds of women acquainted with it (a take-up ratio of 666), then success may be seen to be rather limited. In any case, it must not be overlooked that fertility rates in South Asia and Latin America, represented by the countries listed, are amongst the highest in the world.

A mixture of success and failure is also typical of policies to rehabilitate low fertility, which are currently being pursued in about 15 countries. Many 
social reforms and adaptation of institutions complementary to modern economic development have made it possible for the individual to freely decide on birth and child spacing. This is a major human achievement which enhances the development of the human person. However, it has had a surprisingly adverse effect on aggregate fertility and population reproduction. In response to this, new institutions and policy measures are being introduced with the objective to re-establish fertility at the socially desirable level.

These institutions and measures are not new. Some were first inaugurated by France and Belgium more than sixty years ago, others developed in the context of the Scandinavian approach in the late Thirties, and still others arose as part of post-war population policies, notably in the socialist countries of Europe. As it stands now, the system of government intervention is quite sophisticated and comprehensive, manipulating many, if not all, of the factors affecting fertility. Yet, it fails to produce the desired effects on the reproductive behavior of the person and the population. Except, perhaps in the case of two or three countries where deficient, low fertility has been raised to slightly above replacement.

\section{Urgent need for more information on fertility}

When problems are persistent and policy measures fail to produce the anticipated effects, greater knowledge becomes crucial. Greater information in general, and statistical data in particular, are needed as a basis for research and analysis.

There is little need to demonstrate that additional information on, and knowledge about, fertility are urgently needed if more effective policies are to be devised. Vital statistics and population census data, as major sources of information on fertility level and patterns, and changes in them, are generally good in the industrialized countries. But they are either deficient or absent in most developing countries. In some of the latter, some information has been gathered through KAP studies and occasional fertility surveys, which have provided some material for estimates. But there are many problems with the early surveys: lack of a systematic approach, defective sampling, inadequate methodology, difficulties in processing the data, insufficient analysis, etc.

The aim of the World Fertility Survey was a systematic collection of fertility data, based on technically sound sample design and methodology, scientifically organized and processed, and analyzed as thoroughly as possible. The value of the WFS was in its dual character: it was a scrupulously conducted field enquiry with a minimal amount of standard analysis and a most of imaginative research on fertility and related topics. Conducted in 64 countries throughout the world, 43 of them in developing regions, it is rightly considered the largest social survey ever undertaken in the world. 
The main strength of the enquiry is its ability to describe fertility levels and trends, and changes therein, in each individual country and to give international comparative analyses. It examines the effects of Key-intermediate variables on fertility, drawing on supplementary information on knowledge about contraception, practise of family planning, and desired family size, as well as certain socio-economic characteristics. It is not suitable, however, for study of the economics of reproduction, or the macro-economic, structural or institutional determinants of fertility. It is not designed for these purposes, although some studies are being made to determine whether and to what extent these purposes could be served.

The WFS contribution to knowledge is represented so far by more than 30 national reports (23 published in the developing countries), some 100 studies, reports and technical papers published by the WFS Headquarters, and over 200 papers published in technical journals and different conference proceedings. It has also generated a series of international, regional and national technical meetings, workshops and training schemes. The knowledge it has produced is not passive - simply published and put on the shelf. Rather it is an active knowledge that is being reproduced and multiplied by new generations of experts in countries throughout the world.

Most of the data and research emanating from the WFS is policy-related and is being applied by policy-makers and programme managers. A survey conducted in about 20 developing countries indicates a variety of policy-oriented questions that have been answered in full or in part by ad hoc studies based on the survey material. This line of study seems to be of interest in industrialized countries as well. While they already have information on fertility levels and patterns available from their vital statistics and census data, they can draw information on more subtle matters from the enquiry.

Familiar with both the internal and the external features of the WFS, I feel it is a good and well-organized study, despite the defects and shortcomings that necessarily attend such big undertakings. I also feel that the WFS has still to finish its first round off, by enlisting a few large countries of Africa, Asia and Latin America. It should also prepare a second round, to maximize the efforts and resources invested in the first. I hope that in due course, fertility research will become institutionalized in many countries in the world.

Indeed, appropriate extension of fertility research under the WFS program would require substantial financial resources. These are, however, getting increasingly scarce, owing to inflation and economic recession, as well as a change in attitudes. We are told that resources are desperately needed for operational activities, particularly to support population programs. Anyone familiar with the present and future population situation cannot but agree that programs have the highest priority. But the question is, is it possible to design, evaluate and when needed re-shape, a population program without the necessary statistical and scientific underpinnings? 